\title{
The Interaction of lonic Currents Mediating Single Spike Activity in Retinal Amacrine Cells of the Tiger Salamander
}

\author{
Scott Eliasof, Steven Barnes, ${ }^{\mathrm{a}}$ and Frank Werblin \\ Graduate Group in Neurobiology, University of California, Berkeley, California 94720
}

\begin{abstract}
We investigated the ionic interactions responsible for the characteristic nonrepetitive spike activity of amacrine cells. First we measured 4 pharmacologically separable ionic components: a voltage-gated, transient inward sodium current, a voltage-gated, sustained inward calcium current, a calcium-gated, sustained outward potassium current, and a voltage-gated, transient outward potassium current.

The measurements provided the time course and magnitudes of the underlying conductances as functions of voltage. Each current was simulated following conventional Hodgkin-Huxley theory. A composite of the simulated currents was analytically reassembled to generate an approximation of the voltage response to a current step. By artificially varying the magnitude and kinetics of the different conductances in the simulation, we determined the range of values that supported the nonrepetitive spike-like response.

Amacrine cells tend to remain refractory following an initial spike because (1) the entire activation range for potassium is located at positive potentials with respect to sodium inactivation, so sodium inactivation is never fully extinguished, and (2) the fully activated sodium conductance is of insufficient magnitude to subsequently reach threshold, given this residual inactivation. Shifting the sodium inactivation range by $10 \mathrm{mV}$, or increasing sodium conductance by 5 times, leads to a more repetitive form of activity. Changes in the magnitude, time course, or activation range of the potassium conductance cannot alter these conditions.
\end{abstract}

A major class of retinal amacrine cells responds with a nonrepetitive spike-like depolarization to step changes in illumination in a variety of vertebrates, including mudpuppy (Werblin and Dowling, 1969), fish (Kaneko, 1970), turtle (Marchiafava and Torre, 1978), cat (Grüsser, 1979), and rabbit (Dacheux and Miller, 1981). These cells seem to form the change-sensitive lateral inhibitory surround of most ganglion cells. An inhibitory input with similar time course has been measured in all ganglion cell types in salamander (Werblin and Copenhagen, 1974; Thibos and Werblin, 1978; Wunk and Werblin, 1978) and in cat Y-cells (Saito and Fukada, 1975).

The gated membrane currents in these amacrine cells play a

\footnotetext{
Received Sept. 26, 1986; revised May 18, 1987; accepted May 20, 1987

This work was supported by NIH Grant EY00561 to F.W. and NIH Training Grant GM07048 to S.B. and S.E. We wish to thank Dr. Peter D. Lukasiewicz for his help in performing certain key experiments.

Correspondence should be addressed to Frank Werblin, Graduate Group in Neurobiology, University of California, Berkeley, CA 94720.

apresent address: Department of Physiology and Biophysics, University of Washington, Seattle, WA 98195

Copyright C 1987 Society for Neuroscience $0270-6474 / 87 / 113512-13 \$ 02.00 / 0$
}

key role in generating the transient response (Barnes and Werblin, 1986). The amacrine cell response remains transient even when the membrane is depolarized by a sustained injected current (Werblin, 1977; Marchiafava and Torre, 1978; Barnes and Werblin, 1986). Gated currents boost the leading edge of the response, generating a spike-like depolarization, but then act to limit activity to only 1 or 2 spikes (Barnes and Werblin, 1986).

We have investigated how the interaction of the ionic conductances forms the nonrepetitive, transient amacrine cell response. First, we identified, measured, and characterized the pharmacologically separable currents that contribute to the response. These currents were then analyzed according to conventional Hodgkin-Huxley theory (1952) to derive characteristics of the underlying ionic conductances. The conductances were then used to reconstruct the characteristic voltage response. In the simulation, we could observe and analyze the interactions of the individual ionic conductances while artificially varying their magnitudes and kinetics. Our analysis shows surprising stability the nonrepetitive nature of the response is preserved over a broad range of artificially altered magnitudes and kinetics. Beyond this range, the cell begins to generate more conventional repetitive spike activity.

\section{Materials and Methods}

Cell identification and slices. Retinal sliccs wcre prepared in room light as described by Werblin (1977). Cells along the inner margin of the inner plexiform layer were studied. To verify their identity, 8 cells were filled with Lucifer yellow (Stewart, 1978). Each cell had a morphology similar to a type I amacrine cell, described by Wong-Riley (1974). All cells reported here had similar electrical properties.

Solutions. A standard amphibian Ringer's solution was modified to allow the isolation and study of various membrane currents (Table 1). Solutions were introduced and drained using peristaltic pumps. The preparation chamber had a volume of less than $1 \mathrm{ml}$ and solutions could be completely exchanged in $1 \mathrm{~min}$, although more rapid drug effects were usually observed.

Electrodes. Patch electrodes with a tip resistance of 5-10 M $\Omega$ were pulled on a Kopf vertical electrode pulle: With the use of thin-walled borosilicatc glass with $1.5 \mathrm{~mm}$ O.D. (WP Instruments; TW-150), sharply tapering electrodes that did not require fire-polishing were obtained with a single pull. Electrodes were normally filled with an intracellular solution consisting of $116 \mathrm{~mm} \mathrm{KCl,} 1 \mathrm{~mm}$ EGTA, $4 \mathrm{~mm}$ HEPES, and 0.1 $\mathrm{mM} \mathrm{CaCl}_{2}, \mathrm{pH}$ of 7.5 , measured at room temperature. Free calcium was buffered to $10^{-8} \mathrm{M}$.

Patch-clamp electronics. Membrane currents and voltage were recorded using standard patch-clamp electronics (Hammill et al., 1981) with a $1 G \Omega$ resistor in the current-to-voltage converter. Capacitance compensation and series resistance compensation were employed.

Space-clamp conditions. Care was taken to ensure an adequate spaceclamp of the soma before interpreting the results. Cells judged to be poorly voltage-clamped showed uncontrolled regenerative inward currents, often in conjunction with low seal resistances. Such cells were not included in these results.

Passive membrane properties. Under voltage-clamp, the input resis- 
Table 1. Bathing solutions

\begin{tabular}{|c|c|c|c|c|c|c|c|}
\hline & \multicolumn{7}{|c|}{ Concentrations (mM) } \\
\hline & $\mathrm{NaCl}$ & $\mathrm{KCl}$ & $\mathrm{CaCl}_{2}$ & $\mathrm{MgCl}_{2}$ & HEPES & $\begin{array}{l}\text { TEA } \\
\mathrm{Cl}\end{array}$ & $\begin{array}{l}\text { Cho- } \\
\text { line } \\
\text { Cl }\end{array}$ \\
\hline Normal & 108 & 2 & 3 & 1 & 4 & 0 & 0 \\
\hline Low $\mathrm{Ca}^{2+}$ & 108 & 2 & 1 & 3 & 4 & 0 & 0 \\
\hline Choline & 0 & 2 & 3 & 1 & 4 & 0 & 108 \\
\hline Choline/TEA & 0 & 2 & 3 & 1 & 4 & 20 & 88 \\
\hline
\end{tabular}

Composition of the bathing solutions used in the various experiments. The top row is the normal amphibian Ringer's. The other rows are the solutions used as discussed in the text.

tance was calculated by measuring the current resulting from $10-20 \mathrm{mV}$ hyperpolarizations from the holding level (where no gated currents were activated). The resistances varied between 1 and $4 \mathrm{G} \Omega$. The capacitance was calculated from the time constant of the relaxation of the capacitive current. The average value was $20 \mathrm{pF}$. Given that the specific capacitance of a membrane is about $1 \mu \mathrm{F} / \mathrm{cm}^{2}$, we calculated a membrane surface arca of $2000 \mu \mathrm{m}^{2}$. If the soma is approximated as a spherical cell with a $15 \mu \mathrm{m}$ diameter, the membrane area is approximately $710 \mu \mathrm{m}^{2}$. Thus, almost two-thirds of this area must consist of dendrites and membrane infoldings. Using a membrane area of $2000 \mu \mathrm{m}^{2}$ and an input resistance of $2 \mathrm{G} \Omega$, the specific membrane resistance would be $40 \mathrm{k} \Omega-\mathrm{cm}^{2}$.

Ionic reversal potentials. In order to compute ionic conductances on the basis of isolated currents measured under voltage-clamp, the driving force must be known. For sodium and calcium, the reversal potentials were determined by linear extrapolation of the current-voltage relations over the potential range in which the conductances are fully activated. The reversal potential for sodium, measured by linear extrapolation in the range from -10 to $+20 \mathrm{mV}$, was $+50 \mathrm{mV}$ (see Fig. $1 B$ ). Although there is no sodium in the electrode solution, this indicates an intracellular concentration of $15 \mathrm{~mm}$, perhaps the result of accumulation during cell activity or internal buffering.

The reversal potential for calcium, measured in the same way, was $+51 \mathrm{mV}$ (see Fig. 5). This is considerably lower than the calculated Nernst potential of $+160 \mathrm{mV}$. The difference may be the result of the flow of monovalent cations out through calcium channels (Reuter and Scholz, 1977). Since the cell is loaded with cesium in order to block outward currents, the outward current would be carried by cesium. For the simulations, we assumed $E_{\mathrm{Ca}}$ was $+51 \mathrm{mV}$ (see Table 2).

The reversal potential for potassium was difficult to measure, since most of the current was calcium-activated, and the accompanying inward calcium current interfered with measurements of the outward potassium current. The Nernst potential calculated from the known intracellular and extracellular potassium concentrations is $-103 \mathrm{mV}$, and this value was used in the simulations for $E_{\mathrm{K}}$ and $E_{\mathrm{IA}}$ (see Table 2).

Computer-aided data acquisition and analysis. Signals were amplified with standard variable-gain amplifiers, digitized by a 12-bit resolution Data Translations DT2801 analog-to-digital converter and recorded on an IBM PC/XT computer. Playback and analysis could then be performed with single precision arithmetic BASIC programs. Curve-fitting routines used the least-squares method of minimization. Differential equations were solved using Euler's method, with a step size of 0.01 msec. Smaller step sizes did not significantly improve the solution.

Hodgkin-Huxley analysis. The separate currents were analyzed using the quantitative methods of Hodgkin and Huxley (1952) and Conner and Stevens (1971). We assumed that the soma was well space-clamped, so that all the active ionic conductances were located electrotonically close to the patch electrode. Therefore, no passive partitions were included. The ionic conductances for a range of pulse potentials can be entirely described by activation and (in the case of sodium and $I_{\mathrm{A}}$ ) inactivation variables raised to some power. These variables are all solutions to first-order differential equations of the form

$$
\frac{d x(V, t)}{d t}=\frac{x_{\infty}(V)-x(V, t)}{\tau_{x}(V)},
$$

where $x_{r}$ and $\tau_{\mathrm{x}}$ are descriptions of the steady-state level of activation (or inactivation) and the time constant, respectively. The solution to
Table 2. Simulation parameters

\begin{tabular}{rlrl}
\hline $\mathrm{Cm}$ & $=20 \mathrm{pF}$ & & $E_{\text {rest }}=-80 \mathrm{mV}$ \\
$R_{\mathrm{in}}$ & $=950 \mathrm{M} \Omega$ & $G_{\mathrm{Na}}$ & $=21 \mathrm{nS}$ \\
$E_{\mathrm{Na}}$ & $=+50 \mathrm{mV}$ & $G_{\mathrm{K}}$ & $=17 \mathrm{nS}$ \\
$E_{\mathrm{K}}$ & $=-103 \mathrm{mV}$ & $G_{\mathrm{Ca}}$ & $=3.3 \mathrm{nS}$ \\
$E_{\mathrm{Ca}}$ & $=+51 \mathrm{mV}$ & $G_{\mathrm{IA}}$ & $=5.4 \mathrm{nS}$ \\
$E_{\mathrm{lA}}$ & $=-103 \mathrm{mV}$ &
\end{tabular}

Parameters used to simulate the current and voltage traces. Listed here are the passive membrane properties, the ionic reversal potentials, and the maximum ionic conductances. Figures for the kinetics and magnitudes used in the simulations are as shown in the text.

this differential equation for a step of potential is

$$
x(V, t)=x_{\infty}(V)-\left(x_{\infty}(V)-x_{0}\right) e^{-t / \tau_{\mathrm{x}}(v)}
$$

where $x_{0}$ is the initial value (at rest). Since $x_{\infty}$ and $\tau_{\mathrm{x}}$ are functions only of membrane potential, the currents measured under voltage-clamp were completely described once the voltage dependence of these 2 variables are known. Once the values of $\tau_{x}$ and $x_{\infty}$ were determined at several pulse potentials, a lookup table was generated in which all values between data points were approximated by linear interpolation.

To compute the voltage response to a step of current, the differential equations for the different conductances were solved at each potential. These equations were solved simultaneously with the differential equation describing the voltage change for the whole membrane:

$$
\frac{d V}{d t}=\frac{I_{\mathrm{app}}-I_{\mathrm{Na}}-I_{\mathrm{IA}}-I_{\mathrm{K}}-I_{\mathrm{Ca}}-I_{\text {leak }}}{C}
$$

where $I_{\mathrm{app}}$ is the applied step of current, $\mathrm{I}_{\text {teak }}$ is the current due to the resting conductance (i.e., $1 / R_{\mathrm{in}}$ ), which is assumed to reverse at rest, and the other currents are as described in Results.

\section{Results}

From the measurements of each of 4 pharmacologically separable ionic currents, we were able to mcasure the activation (and inactivation) variables and the kinetics as a function of potential. The analysis of these measurements allowed us to simulate each current, and compare the simulation with the measured results for verification of our analysis. The measurement and analysis of each current component is outlined below.

\section{Transient inward current}

A transient inward current was isolated using a low-calcium, high-magnesium bathing medium (Table 1) to eliminate the calcium currents, and replacing the $116 \mathrm{~mm} \mathrm{KCl}$ with $\mathrm{CsCl}$ in the electrode to eliminate the potassium currents (Thompson and Aldrich, 1980). The transient inward current could be eliminated by replacing sodium with choline in the bathing medium, or by adding $1 \mu \mathrm{M}$ TTX.

The voltage-dependent activation of the transient inward current was derived from current measurements as the membranc was stepped to various command potentials from a holding potential of $-65 \mathrm{mV}$, as shown in Figure $1 \mathrm{~A}$. The inward current began to appear at $-30 \mathrm{mV}$, and was maximum (for this cell) at $-13 \mathrm{mV}$, suggesting a narrow activation range spanning only $20 \mathrm{mV}$. Figure $1 B$ shows the magnitude of the peak current plotted as a function of voltage. The maximum inward current for this cell $(-475 \mathrm{pA})$ is at the low end of the spectrum for a typical amacrine cell (between -450 and $-750 \mathrm{pA}$ ). As described in Materials and Methods, for command potentials more positive than $-13 \mathrm{mV}$, the magnitude of the current diminishes, and a reversal potential of $+50 \mathrm{mV}$ can be calculated by linear extrapolation. 


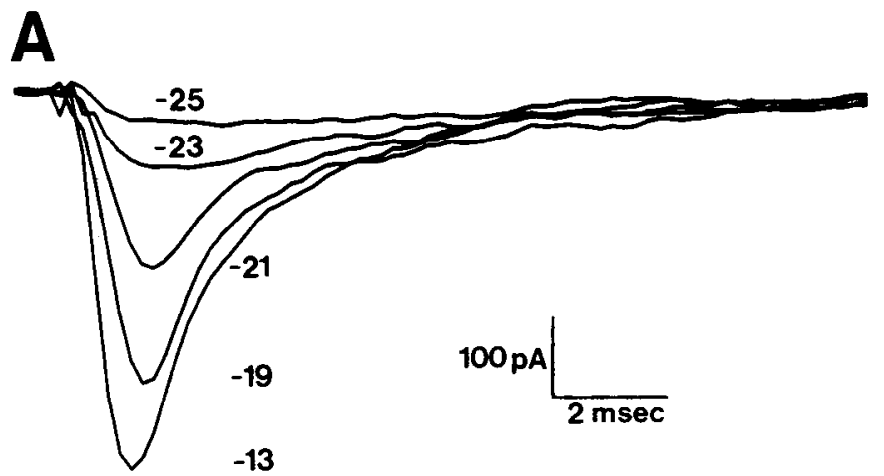

B

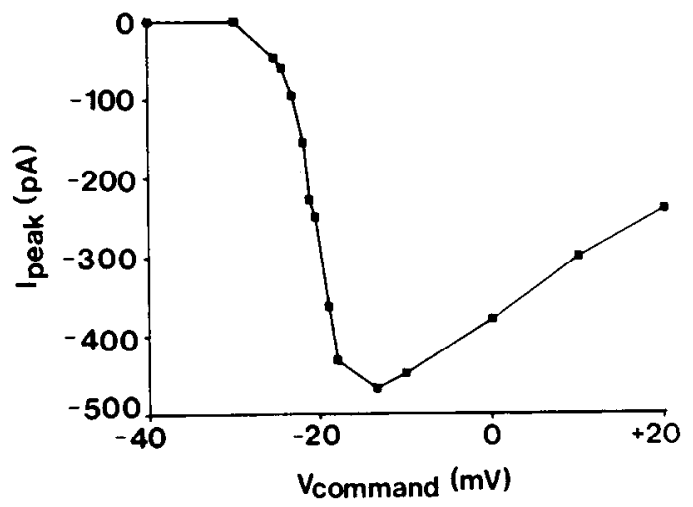

Figure 1. Transient inward current measured under voltage-clamp. $A$, Current responses to command potentials. The numbers beside the current traces indicate the command potentials (in $\mathrm{mV}$ ) to which the membranes were depolarized from a holding potential of $-65 \mathrm{mV}$. The current was isolated by using a low-calcium, high-magnesium bathing solution with cesium replacing potassium in the electrode solution. $\mathrm{Ca}$ pacitive artifacts were removed by subtraction. Bottom trace, stimulus timing. $B$, Peak inward current as a function of command potential. The peak current is maximum at $-13 \mathrm{mV}$, and then diminishes for more positive command potentials, with an extrapolated reversal potential of $+50 \mathrm{mV}$.

According to the conventional analysis of Hodgkin and Huxley (1952), the conductance $g_{\mathrm{Na}}$ was expressed as the product of an activation term, $m$ and an inactivation term, $h$ :

$$
g_{\mathrm{Na}}=G_{\mathrm{Na}} m^{\mathrm{N}} h,
$$

where $G_{\mathrm{Na}}$ is the maximum conductance (see Table 2) and $\mathrm{N}$ is an exponent chosen to fit the shape of the conductance rise. The activation and inactivation terms are solutions to differential equations, as shown in Equation (2) in Materials and Methods. When these equations are solved and substituted into Equation (4), the result is:

$g_{\mathrm{Na}}=G_{\mathrm{Na}}\left[m_{\infty}-\left(m_{\infty}-m_{0}\right) e^{-v_{\tau_{\mathrm{m}}}}\right]^{\mathrm{N}}\left[h_{\infty}-\left(h_{\infty}-h_{0}\right) e^{-\mathrm{L}_{\mathrm{h}}}\right]$

where $\tau_{\mathrm{m}}$ and $\tau_{\mathrm{h}}$ represent the activation and inactivation time constants.

This equation can be simplified because, at rest, the sodium channels are closed but not inactivated, so that initial values are $m_{0}=0$ and $h_{0}=1$. Also, when the membrane is held at any potential that activates the sodium channels (above $-35 \mathrm{mV}$ ), the channels will completely inactivate. That is, $h_{\infty}=0$ above $-35 \mathrm{mV}$. Thus, the sodium conductance can be expressed as:

$$
g_{\mathrm{Na}}=G_{\mathrm{Na}} m_{\infty}^{\mathrm{N}}\left(1-e^{-\mathrm{v}_{\mathrm{m}}}\right)^{\mathrm{N}} e^{-1 / \tau \mathrm{h}}
$$

where $m_{\infty}$ represents the steady-state activation, which the sodium conductance would achieve in the absence of inactivation.

The voltage-dependent inactivation of this current was determined by measuring the peak current in response to a test voltage pulse to $-10 \mathrm{mV}$, evoked following conditioning potentials from -70 to $-30 \mathrm{mV}$, as shown in Figure $2 A$. The current bcgan to inactivate at a conditioning potential of $-50 \mathrm{mV}$ and became progressively smaller, disappearing when the conditioning level was more positive than $-30 \mathrm{mV}$. The test potential was always the same, and steady-state inactivation $\left(h_{\infty}\right)$ can therefore be calculated as the normalized peak current, where a value of 1 indicates no inactivation. Inactivation as a function of command potential is plotted in Figure $2 B$.

The time constant of inactivation, $\tau_{h}$, was determined for each step potential as follows: Since activation is much faster than inactivation, after a few activation time constants the expression $1-e^{-t / \tau_{\mathrm{m}}}$ will approach 1. Thus, from Equation $(5 A)$, we estimated $\tau_{h}$ by calculating the slope of the following equation, plotted on semilogarithmic axes:

$$
g_{\mathrm{Na}}=G_{\mathrm{Na}} m_{\infty}{ }^{\mathrm{N}} e^{-1 / \tau_{\mathrm{h}}} .
$$

Once an initial estimate for the inactivation time constant was derived, an estimate for the activation time constant was also made, based on the known time to peak. Better estimates of the 2 time constants were then obtained by nonlinear curve-fitting techniques. Figure $2 C$ shows the inactivation time constant as a function of voltage.

Activation was studied by eliminating inactivation from Equations (4) and (5) by division. An exponent of 3 was chosen for the activation variable by fitting the sigmoidal shape of the simulated current onset with the data (see Fig. $3 A$ ). Steady-state activation $\left(m_{\omega}\right)$ was then computed for each pulse potential by fitting to the solution of the differential equation:

$$
m=\left[\frac{g_{\mathrm{Na}}}{G_{\mathrm{Na}} e^{-v_{\tau \mathrm{h}}}}\right]^{1 / 3}=m_{\infty}\left(1-e^{-v_{\tau_{\mathrm{m}}}}\right)
$$

Steady-state activation as a function of command potential is plotted in Figure $3 B$. Figure $3 C$ shows the activation time constant $\left(\tau_{m}\right)$ as a function of voltage, computed as described above. Finally, the computed activation variables and time constants as functions of voltage were used to simulate the sodium currents; a comparison with the measured data is shown in Figure 4.

\section{Sustained inward current}

A sustained inward current could be measured by blocking the sodium and potassium currents. The sodium current was eliminated by substituting choline for sodium in the bathing medium (Table 1); the potassium current was eliminated by using a cesium-filled recording electrode. The inward current could be blocked by adding $1 \mathrm{~mm}$ cobalt to the bathing medium, which suggests that it is carried by calcium ions. The response to a series of depolarizing steps in $10 \mathrm{mV}$ increments is shown in Figure $5 A$. The sustained inward current began to appear near $-30 \mathrm{mV}$. It was largest, typically near $0 \mathrm{mV}$.

Only the calcium-activation process was analyzed here, because the inactivation time constant of more than $250 \mathrm{msec}$ is 

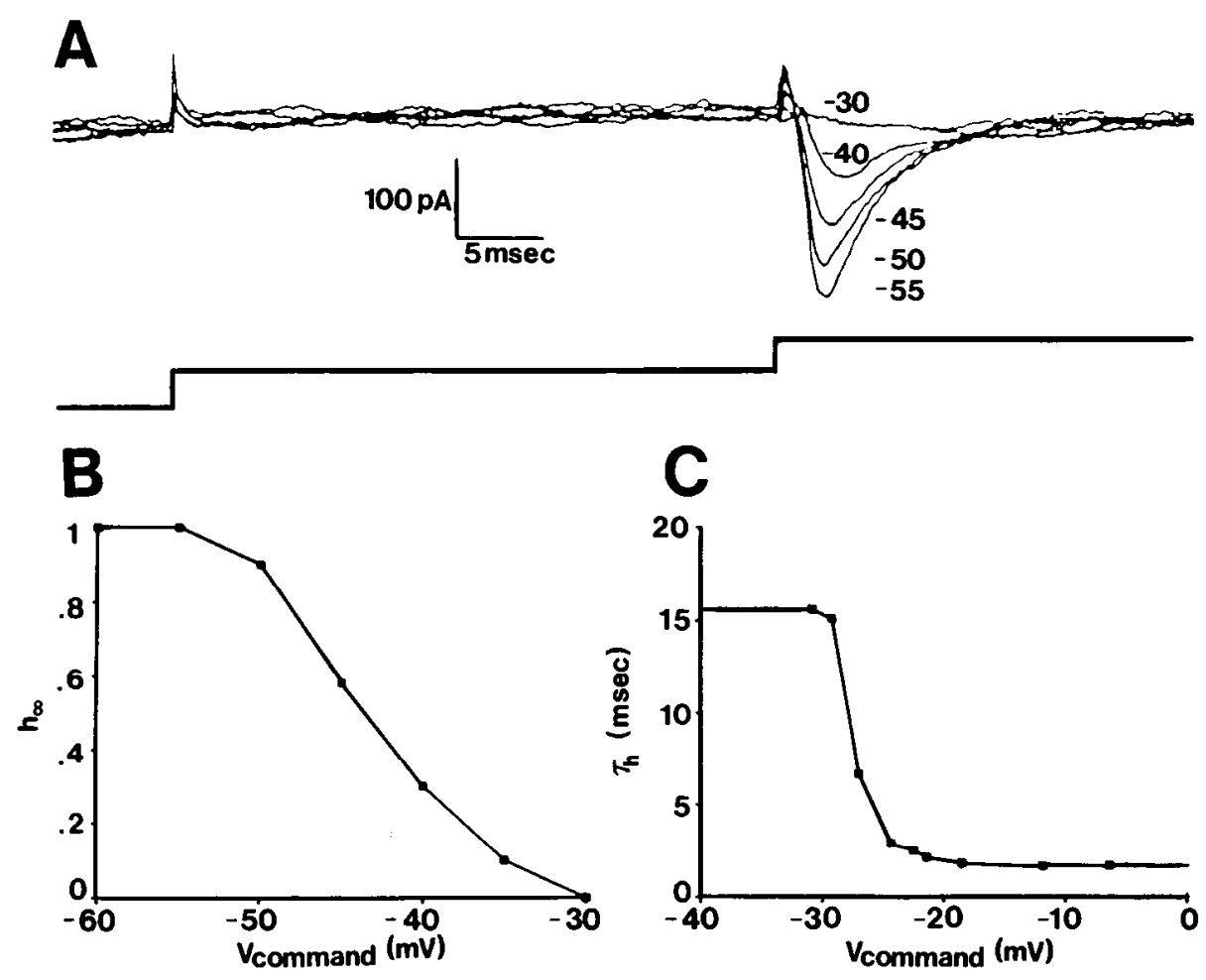

Figure 2. Voltage-dependent inactivation of the transient inward current. $A$, Current responses following conditioning steps. Inactivation was measured by preceding a test potential to $-10 \mathrm{mV}$ by $35 \mathrm{msec}$ conditioning potentials ranging from -60 to $30 \mathrm{mV}$. The numbers beside the current traces indicate the conditioning potentials (in $\mathrm{mV}$. Bottom trace, stimulus timing. $B$, Steady-state inactivation $\left(\mathrm{h}_{\infty}\right)$ as a function of conditioning potential. Since the test potential (and hence the driving force) is constant, this curve is calculated from the normalized peak inward current in $A$. $C$, Inactivation time constant $\left(\tau_{h}\right)$ as a function of command potential. This was derived as described in the text.

4 times greater than the $60 \mathrm{msec}$ period over which the response was simulated. The calcium conductance was therefore expressed in terms of the activation variable, $p$ :

$$
g_{\mathrm{Ca}}=G_{\mathrm{Ca}} p^{\mathrm{N}}
$$

where $G_{\mathrm{Ca}}$ is the maximum conductance (see Table 2) and $\mathrm{N}$ is an exponent chosen to fit the shape of the conductance rise. Applying the solution to the activation differential equation [Equation (2)], and considering the fact that the calcium channels are closed at rest (i.e., $p_{0}=0$ ), the calcium conductance can be rewritten as

$$
g_{\mathrm{Ca}}=G_{\mathrm{Ca}} p_{\infty}\left(1-e^{-\mathrm{v} / p}\right)^{\mathrm{N}}
$$

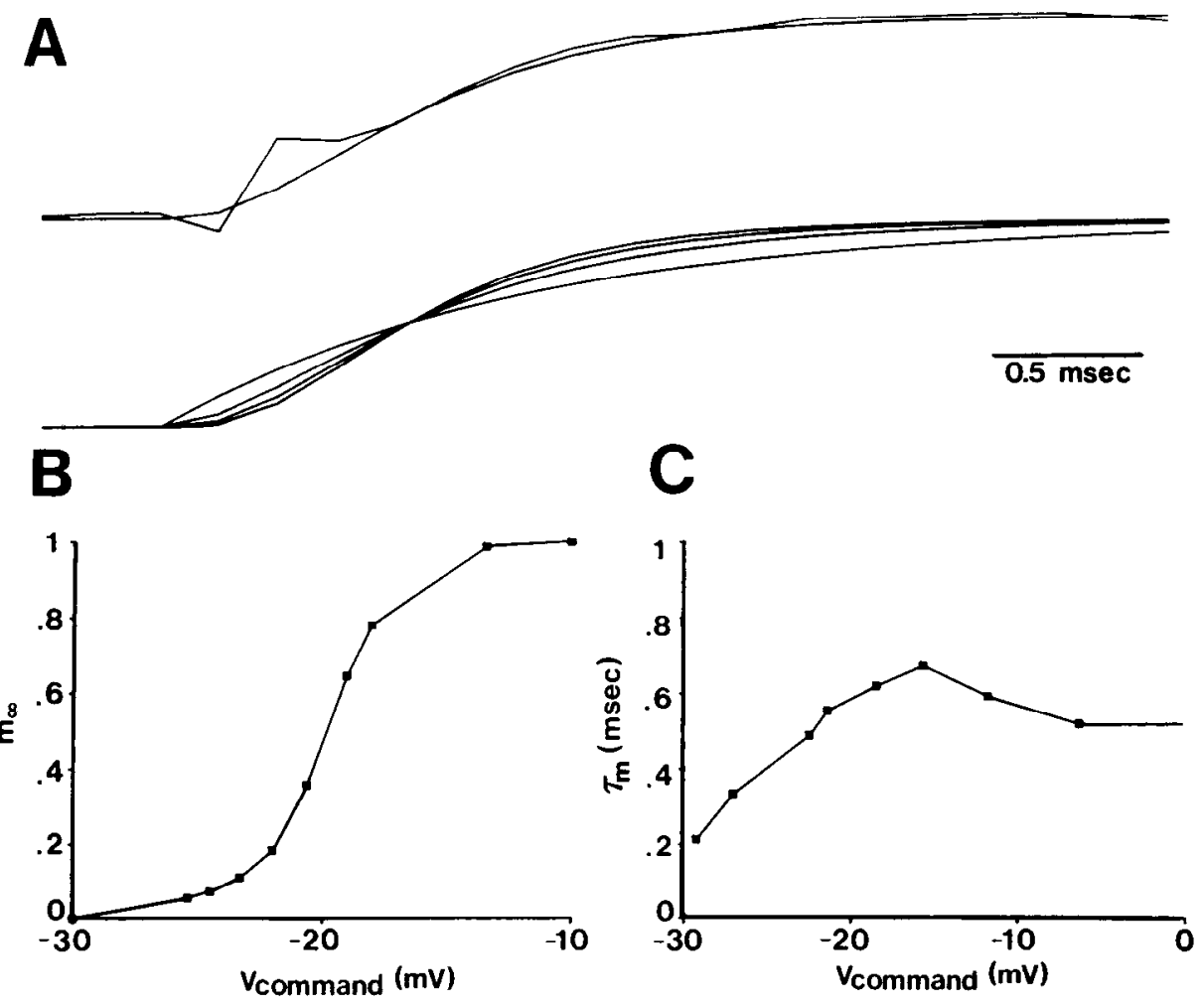

Figure 3. Voltage-dependent activation of the transient inward current. $A$, An activation exponent of 3 was determined by curve-fitting to the current onset. Here, the current response to a command potential of $-27 \mathrm{mV}$ was used. The inactivation term (with a time constant of $6.64 \mathrm{msec}$ ) was eliminated by division [see Equation (7)], leaving a rising exponential. The top trace shows the data superimposed with a simulated rising exponential having an exponent of 3. Bottom traces, series of simulated rising exponentials having exponents ranging from 1 (no delay) to 6 (maximum delay). The time constants are chosen such that they all reach halfmaximum at the same time. $B$, Steadystate activation $\left(m_{\infty}\right)$ as a function of command potential was calculated as the cube root of the normalized conductance after eliminating the inactivation term by division. $C$, Activation time constant $\left(\tau_{\mathrm{m}}\right)$ as a function of command potential. This was derived by curve-fitting to Equation (7), using an exponent, $N$, of 3 . 


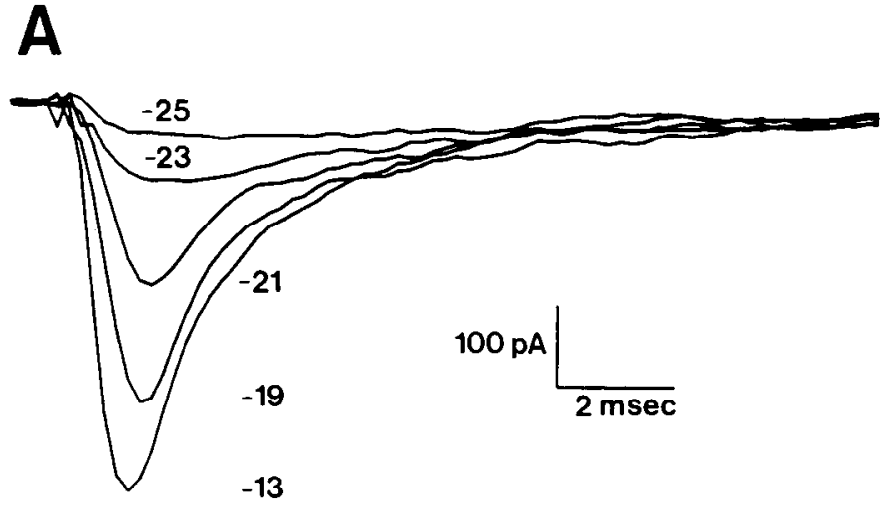

B

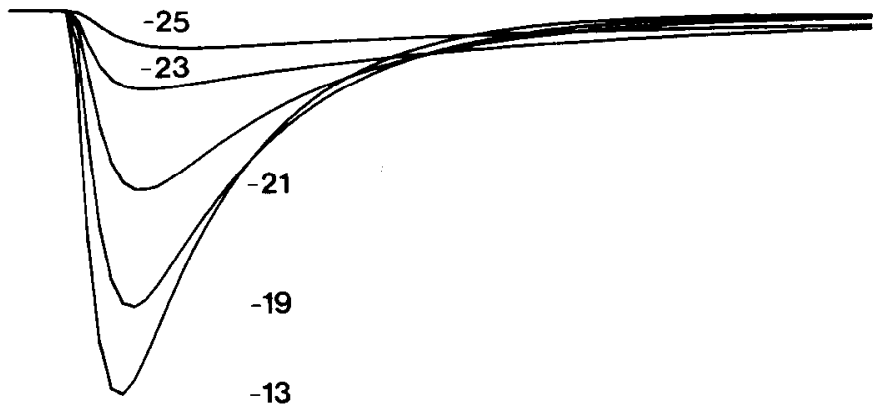

Figure 4. A comparison of measured and simulated transient inward currents. $A$, Measured transient inward current, redrawn from Figure $1 A$. Capacitive artifacts were removed by subtraction. $B$, Simulated transient inward current, calculated using the data shown in previous figures. The numbers beside the current traces indicate the command potentials (in $\mathrm{mV}$ ) to which the membrane was depolarized from a holding potential of $-65 \mathrm{mV}$. Bottom trace, stimulus timing.

where $p_{\infty}$ is the steady-state activation, and $\tau_{\mathrm{p}}$ is the activation time constant. By fitting the curves derived from the above equation to the measured current onset, the exponent $\mathrm{N}$ was determined to be 2 (see Fig. $6 A$ ). Thus, the magnitude of steadystate activation was given as the square root of the normalized conductance curve (see Fig. $6 \mathrm{~B}$ ). Figure $6 \mathrm{C}$ shows the activation time constant $\left(\tau_{\mathrm{p}}\right)$ as a function of voltage. Figure 7 shows the measured and simulated calcium currents. The 2 sets of curves are quite similar; they differ slightly because inactivation was not included in the simulated calcium current.

\section{Sustained outward current}

The outward current can be isolated by substituting choline for sodium in the bathing medium (Table 1). All outward current could be eliminated by replacing the potassium with cesium in the electrode solution, which suggests that the current is carried by potassium ions. About $80 \%$ of this current could be eliminated with $20 \mathrm{~mm}$ tetraethylammonium (TEA), or by substituting $3 \mathrm{~mm}$ cobalt for calcium in the bathing medium. These findings suggest that this is a calcium-dependent potassium current sensitive to TEA, similar to that seen by Meech and Standen (1975).
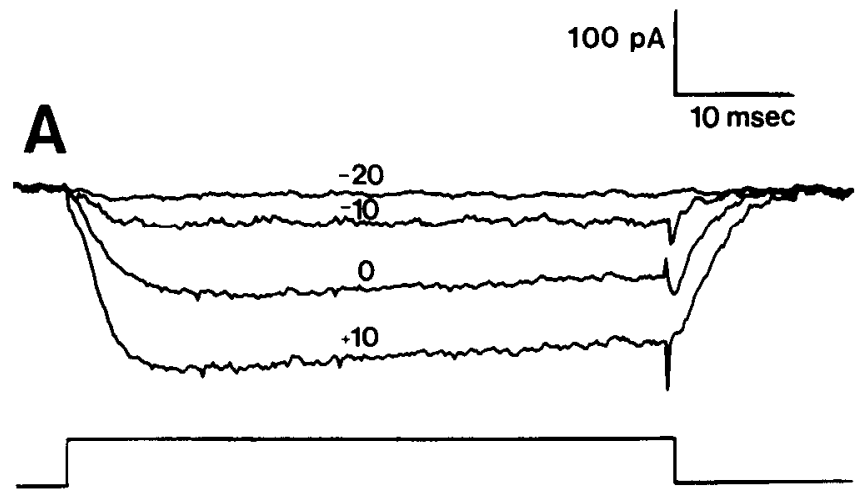

B

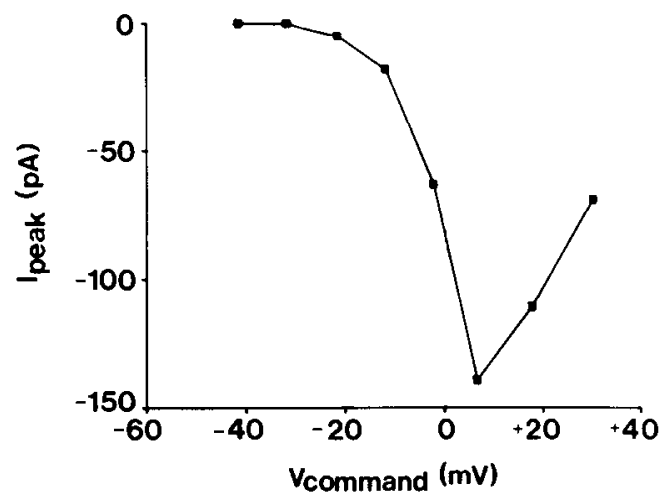

Figure 5. Sustained inward current measured under voltage-clamp. $A$, Current responses to command potentials. The numbers beside the current traces indicate the command potentials (in $\mathrm{mV}$ ) to which the membrane was depolarized from a holding potential of $-65 \mathrm{mV}$. The current was isolated by substituting choline for sodium in the bathing solution, and cesium for potassium in the electrode solution. Capacitive artifacts were removed by subtraction. $B$, Peak inward current as a function of command potential. The peak current is maximum at $-13 \mathrm{mV}$ and then diminishes for more positive command potentials, with an extrapolated reversal potential of $+50 \mathrm{mV}$.

Part of the outward current was normally offset by the inward calcium component (see previous section). In order to measure the properties of the outward current alone, we eliminated the contribution of calcium by subtracting records obtained in the presence of TEA from those obtained in its absence. The traces in Figure $9 A$ show that this outward current began to appear at about $-20 \mathrm{mV}$, and increased in magnitude to over $2 \mathrm{nA}$ at $+40 \mathrm{mV}$. Strictly speaking, this is a measure only of the TEAblocked component, accounting for $80 \%$ of the net outward current.

We begin by considering the conductance in terms of a voltage-dependent activation variable, $n$ :

$$
g_{\mathrm{K}}=G_{\mathrm{K}} n^{\mathrm{N}} \text {, }
$$

where $G_{\mathrm{K}}$ is the maximum conductance (see Table 2) and $\mathrm{N}$ is an exponent chosen to fit the shape of the conductance rise. Substituting the solution of the activation variable differential equation [Equation (2)], and considering that the potassium channels are closed at rest (i.e., $n_{0}=0$ ),

$$
g_{\mathrm{K}}=G_{\mathrm{K}} n_{\infty}\left(1-e^{-\mathrm{t} / \tau_{\mathrm{n}}}\right)^{\mathrm{N}} \text {. }
$$

Fitting the curves derived from this equation to the measured 


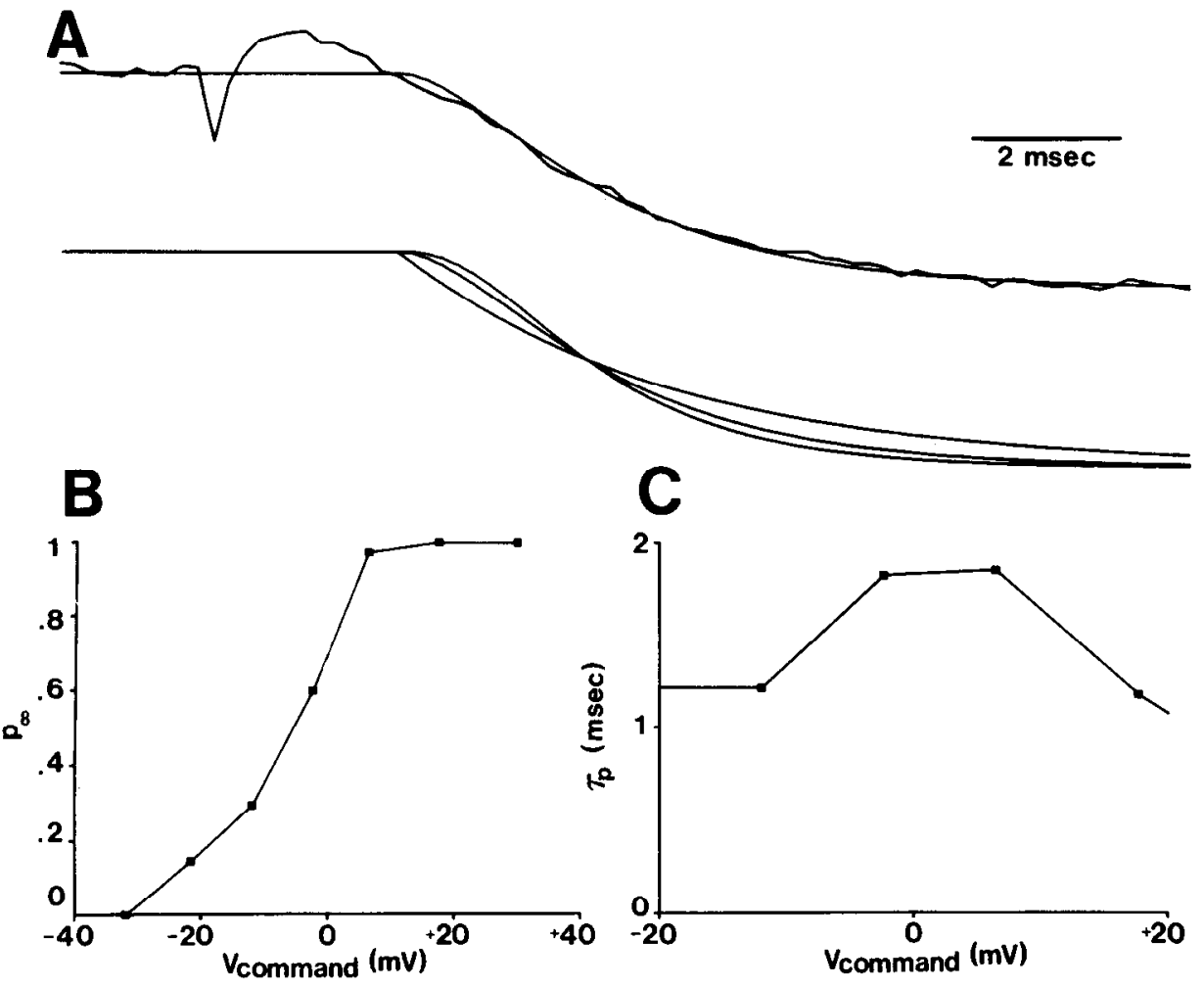

Figure 6. Voltage-dependent activation of the sustained inward current. $A$, An activation exponent of 2 was determined by curve-fitting to the current onset. Here, the current response to a command potential of $0 \mathrm{mV}$ was used. The top trace shows the data superimposed on a simulated rising exponential having an exponent of 2 . Bottom traces, a series of simulated rising exponentials having exponents ranging from 1 (no delay) to 4 (maximum delay). The time constants are chosen such that they all reach half-maximum at the same time. $B$, Steady-state activation $\left(p_{\infty}\right)$ as a function of command potential, calculated as the square root of the normalized conductance. Since the reversal potential could not be measured directly, the normalized conductance curve was measured by the magnitude of the tail currents. $C$, Activation time constant $\left(\tau_{p}\right)$ as a function of command potential. currents, the best value for $\mathrm{N}$ was 1 (Fig. 8A), consistent with results found by Woolum and Gorman (1981).

The necessary delay of the potassium conductance in a standard delayed rectifier arises partly because the slope of the potassium conductance as a function of time is not zero initially (i.e., the exponent $\mathrm{N}$ is greater than 1). In our case, however, $\mathrm{N}$ is 1 , and the delay occurs because potassium activates with a much longer time constant than does sodium, allowing sodium to activate and an action potential to occur before the sodium current is offset by the potassium current (see Discussion).

Since $N$ was 1 , the steady-state activation was given by the normalized conductance curve, as shown in Figure $8 B$. The activation time constant $\left(\tau_{n}\right)$ as a function of command potential was derived from the exponent of the rising phase of the conductance, and is shown in Figure $8 C$. Figure 9 shows that a close similarity between the simulated and measured currents can be achieved.

The potassium conductance is cobalt-blockable, indicating that it is activated by intracellular calcium as well as voltage. Thus, the kinetics and magnitude of this conductance may change as a function of intracellular calcium concentration. Since calcium flows into the cell during an action potential, calcium will accumulate near the inside membrane, and the repolarization may be governed by different magnitudes and kinetics. Fxperiments were performed to test the effect of this calcium accumulation on the magnitude and kinetics of the potassium conductance. Currents were measured in response to both depolarizing steps from a rest level of $-80 \mathrm{mV}$ and hyperpolarizing steps from a $10 \mathrm{msec}$ prepulse to $+10 \mathrm{mV}$, a level where calcium entry is maximal (see Fig. 5). This prepulse is larger and longer in duration than the action potential of an amacrine cell (see Fig. 13), and represents a worst-case estimate of the amount of calcium accumulation that could exist during the membrane's repolarization phase.

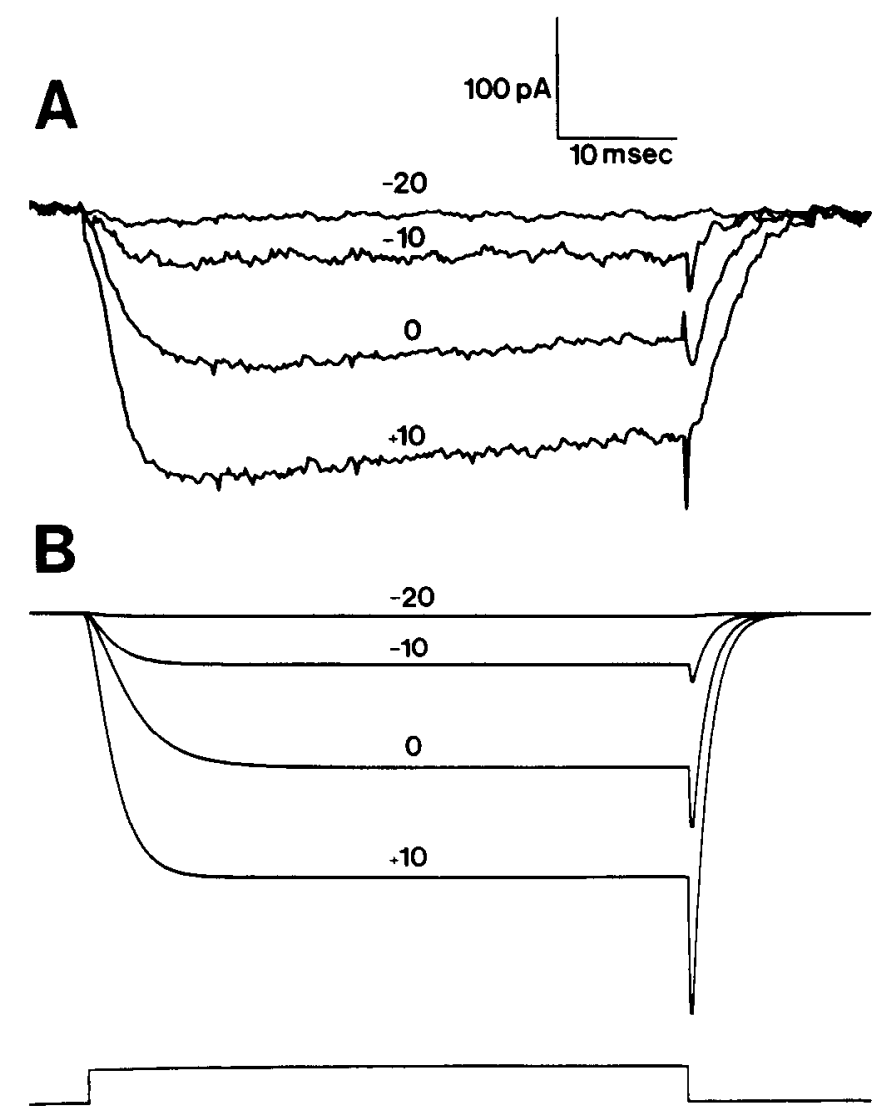

Figure 7. A comparison of measured and simulated sustained inward currents. $A$, Measured sustained inward current, redrawn from Figure $5 A$. Capacitive artifacts were removed by subtraction. $B$, Simulated sustained inward current, calculated using the data shown in the previous figures. Bottom trace, stimulus timing. 
Figure 8. Voltage-dependent activation of the sustained outward current. $A$, An activation exponent of 1 was determined by curve-fitting to the current onset. Here, the current response to a command potential of $+10 \mathrm{mV}$ was used. The top trace shows the data superimposed on a simulated rising exponential having an exponent of 1. Bottom traces, a series of simulated rising exponentials with exponents ranging from 1 (no delay) to 3 (maximum delay). The time constants are chosen such that they all reach half-maximum at the same time. $B$, Steady-state activation $\left(n_{\infty}\right)$ as a function of command potential, calculated as the normalized conductance as measured by the magnitude of the tail currents. $C$, Activation time constant $\left(\tau_{n}\right)$ as a function of command potential.

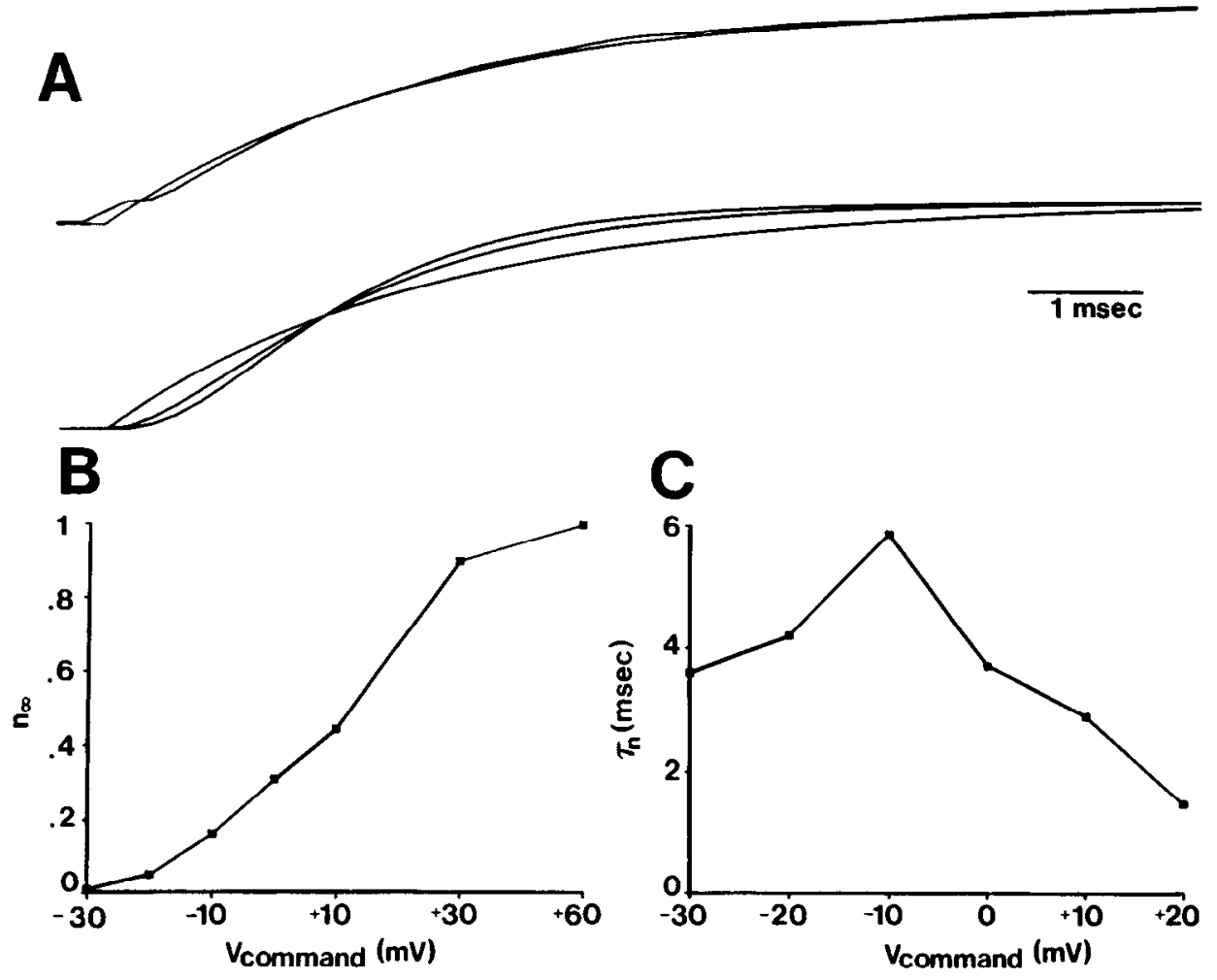

The results of this experiment indicate that the magnitude of the steady-state potassium conductance does not change as a result of the prepulse. However, the kinetics are affected by the conditioning prepulse, and these data are presented in Table 3. Depolarizations from rest to potentials in the range of $-30 \mathrm{mV}$ to $+10 \mathrm{mV}$ elicit currents approximately 3 times faster than do hyperpolarizations from $+10 \mathrm{mV}$ to the same range of potentials. This may reflect the difference between kinetics for calcium accumulation and calcium removal.

\section{Transient outward current}

An additional transient component of outward current could be elicited by depolarizing steps to potentials above $0 \mathrm{mV}$ from a holding potential of $-70 \mathrm{mV}$. This current was transient and could be inactivated by holding the membrane at a conditioning potential more positive than $-30 \mathrm{mV}$. It could also be blocked by $20 \mathrm{~mm}$ 4-AP, but it persisted in the presence of TEA or cobalt, characteristics consistent with the current $I_{\mathrm{A}}$ described by Conner and Stevens (1971) and Thompson (1977). Figure $12 \mathrm{~A}$ shows the isolated transient outward current measured using a choline/TEA bathing solution (Table 1) to block the transient inward and sustained outward currents, with $1 \mathrm{~mm}$ cobalt to block the sustained inward currents.

This conductance, $g_{\mathrm{IA}}$, was taken as the product of an acti-

$\leftarrow$

choline for sodium in the bathing solution. Since most of the potassium current is calcium-activated, the calcium current was eliminated from these records by subtracting the currents measured in the presence and absence of TEA. The current shown here is the component blocked by TEA. Capacitive artifacts were removed by subtraction. $B$, Simulated sustained outward current calculated using the data shown in the previous figure. Bottom trace, stimulus timing.
Figure 9. Comparison of measured and simulated sustained outward currents. $A$, Measured current responses to command potentials. The numbers beside the current traces indicate the command potentials (in $\mathrm{mV}$ ) to which the membrane was depolarized from a holding potential of $-65 \mathrm{mV}$. The transient inward current was eliminated by substituting 

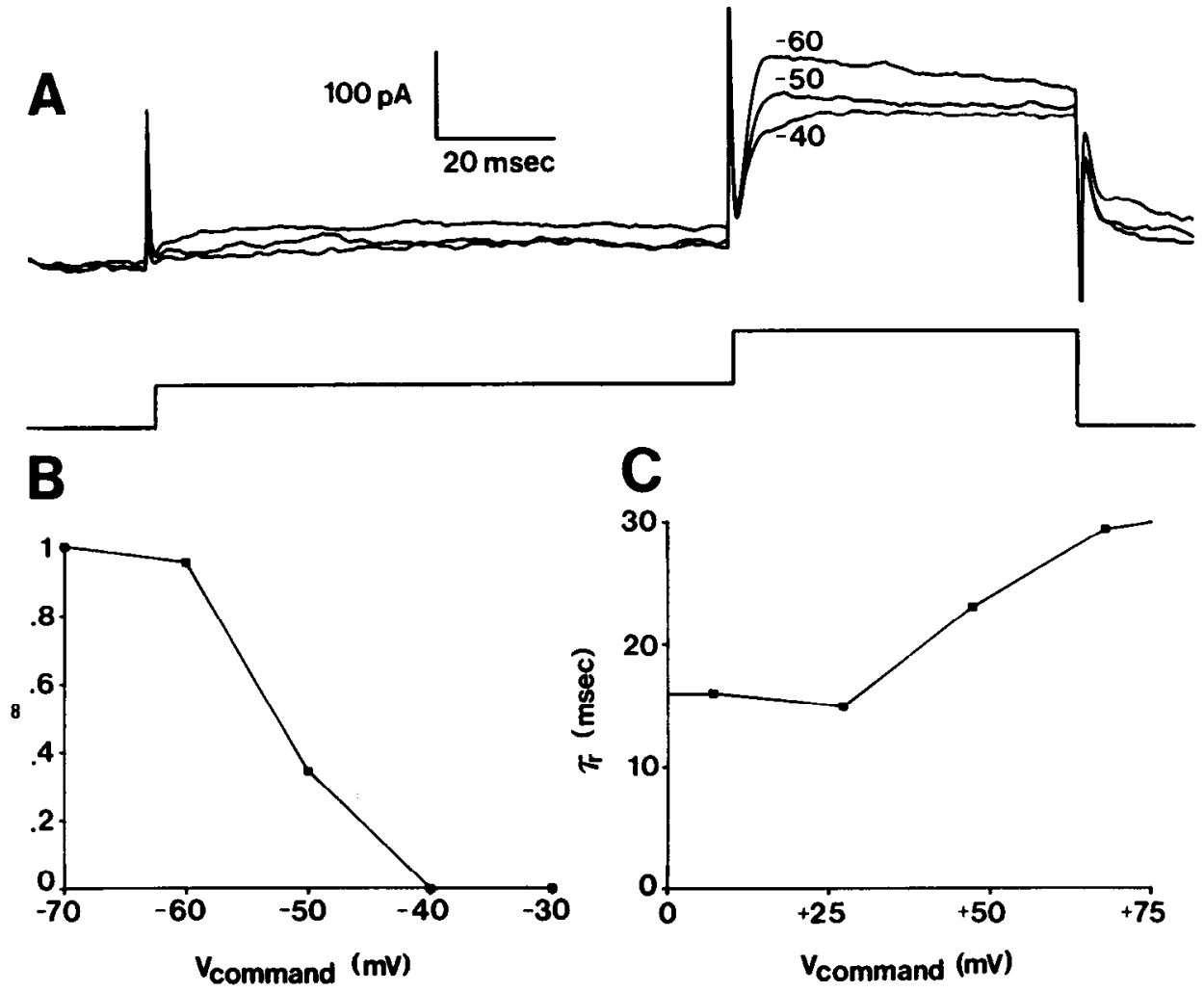

Figure 10. Voltage-dependent inactivation of the transient outward current. $A$, Current responses following conditioning steps. Shown is the inactivation measured by preceding a test potential to $+10 \mathrm{mV}$ with $100 \mathrm{msec}$ conditioning potentials ranging from -60 to -40 $\mathrm{mV}$. Above or below this range, the transient component didn't change much. The numbers beside the current traces indicate the conditioning potentials (in $\mathrm{mV}$ ). Bottom trace, stimulus timing. $B$, Steady-state inactivation $\left(r_{\infty}\right)$ as a function of conditioning potential. This curve is calculated from the normalized difference between the transient and sustained components. $C$, Inactivation time constant $\left(\tau_{\mathrm{r}}\right)$ as a function of command potential. The time constants were measured by plotting the relaxation current on semilogarithmic axes. vation term, $q$, and an inactivation term, $r$, similar to the sodium conductance [see Equation (4)]:

$$
g_{\mathrm{IA}}=q^{\mathrm{N}} r
$$

where $G_{\mathrm{IA}}$ is the maximum conductance (see Table 2) and $\mathrm{N}$ is an exponent chosen to fit the shape of the conductance rise. Again, we can solve the differential equations for the activation and inactivation terms using boundary conditions equivalent to those for sodium (i.e., $q_{0}=0, r_{0}=0$, and $r_{\infty}=1$ ), and obtain an equation similar to Equation $(5 B)$ :

$$
g_{\mathrm{IA}}=G_{\mathrm{IA}} q_{\infty}\left(1-e^{-v_{\mathrm{r}}}\right)^{\mathrm{N}} e^{-\mathrm{v} / \tau_{\mathrm{r}}}
$$

where $q_{\infty}$ represents the steady-state activation, $\tau_{\mathrm{q}}$ and $\tau_{\mathrm{r}}$ represent the activation and inactivation time constants, respectively, and $G_{\mathrm{IA}}$ is the maximum conductance.

The voltage-dependent inactivation was determined by measuring the peak current in response to a test pulse to $+10 \mathrm{mV}$, evoked after holding the membrane for $100 \mathrm{msec}$ at conditioning potentials ranging from -70 to $-30 \mathrm{mV}$, as shown in Figure $10 \mathrm{~A}$. The transient component of the outward current was maximal at conditioning levels more negative than $-60 \mathrm{mV}$, began to inactivate at a conditioning potential of $-50 \mathrm{mV}$, and disappeared when the conditioning level was more positive than $-40 \mathrm{mV}$. The test potential was always the same, and steadystate inactivation $\left(r_{\infty}\right)$ can therefore be calculated as the normalized difference between the transient and sustained components. Inactivation as a function of command potential is plotted in Figure $10 B$.

The inactivation time constant $\left(\tau_{\mathrm{r}}\right)$ can be measured from the relaxation of the $I_{\mathrm{A}}$ conductance (Figure $10 \mathrm{C}$ ). Activation is then isolated by eliminating the inactivation term by division, similar to what was done for the transient inward current. The value for $\mathrm{N}$ was found to lie in the range of 2-4, with 4 fitting best (Fig. $11 \mathrm{~A}$ ). Thus $I_{\mathrm{A}}$ activation was expressed as:

$$
q-\left[g_{\mathrm{IA}} /\left(G_{\mathrm{IA}} e^{-\nu / \tau_{\mathrm{r}}}\right)\right]^{1 / 4}-q_{\infty}\left(1-e^{-\nu / \tau_{\mathrm{q}}}\right) .
$$

Steady-state activation $\left(q_{\infty}\right)$ was given by the fourth root of the normalized conductance-voltage relation, and is shown in Figure $11 B$. The activation time constants $\left(\tau_{\mathrm{q}}\right)$ are shown in Figure $11 C$.

The current was simulated from these results, and a comparison between simulated and measured currents, shown in Figure 12, indicates a close correspondence.

\section{Whole cell response to injected current}

The typical voltage response of an amacrine cell to a range of steps of injected current is shown in Figure $13 A$. The membrane began to depolarize exponentially, with a time constant between 20 and $40 \mathrm{msec}$. This is consistent with measured values of 930 $\mathrm{M} \Omega$ for the cell input resistance and $20 \mathrm{pF}$ for capacitance. When

Table 3. Potassium kinetics

\begin{tabular}{rll}
$\begin{array}{l}V_{\text {command }} \\
(\mathrm{mV})\end{array}$ & $\begin{array}{l}\text { No prepulse } \\
\tau_{\mathrm{n}}(\mathrm{msec})\end{array}$ & $\begin{array}{l}\text { Prepulse } \\
\tau_{\mathrm{n}}(\mathrm{msec})\end{array}$ \\
\hline-20 & 3.4 & 8.8 \\
-10 & 2.8 & 7.7 \\
0 & 2.4 & 8.0
\end{tabular}

A comparison of potassium activation kinetics measured during a depolarization from a rest potential of $-80 \mathrm{mV}$ (No prepulse) and during a hyperpolorization from a $10 \mathrm{msec}$ prepulse to $+10 \mathrm{mV}$ (Prepulse). In the latter case, the activation kinetics are roughly 3 times slower, persumably as a result of an accumulation of intracellular calcium. 
Figure 11. Voltage-dependent activation of the transient outward current. $A$, Activation exponent of 4 determined by curve-fitting to the current onset. Here, the current response to a command potential of $+30 \mathrm{mV}$ was used. The inactivation term was eliminated by division [see Equation (14)], leaving a rising exponential. The top trace shows the data superimposed on a simulated rising exponential having an exponent of 4. Bottom traces, a series of simulated rising exponentials with exponents ranging from 2 (minimum delay) to 5 (maximum delay). Time constants are chosen such that they all reach halfmaximum at the same time. $B$, Steadystate activation $\left(q_{\infty}\right)$ as a function of command potential was calculated as the fourth root of the normalized conductance, after eliminating the inactivation term by division. $C$, Activation time constant $\left(\tau_{\mathrm{q}}\right)$ as a function of command potential. This was derived by curve-fitting to Equation (14), using an exponent, $N$, of 4 .
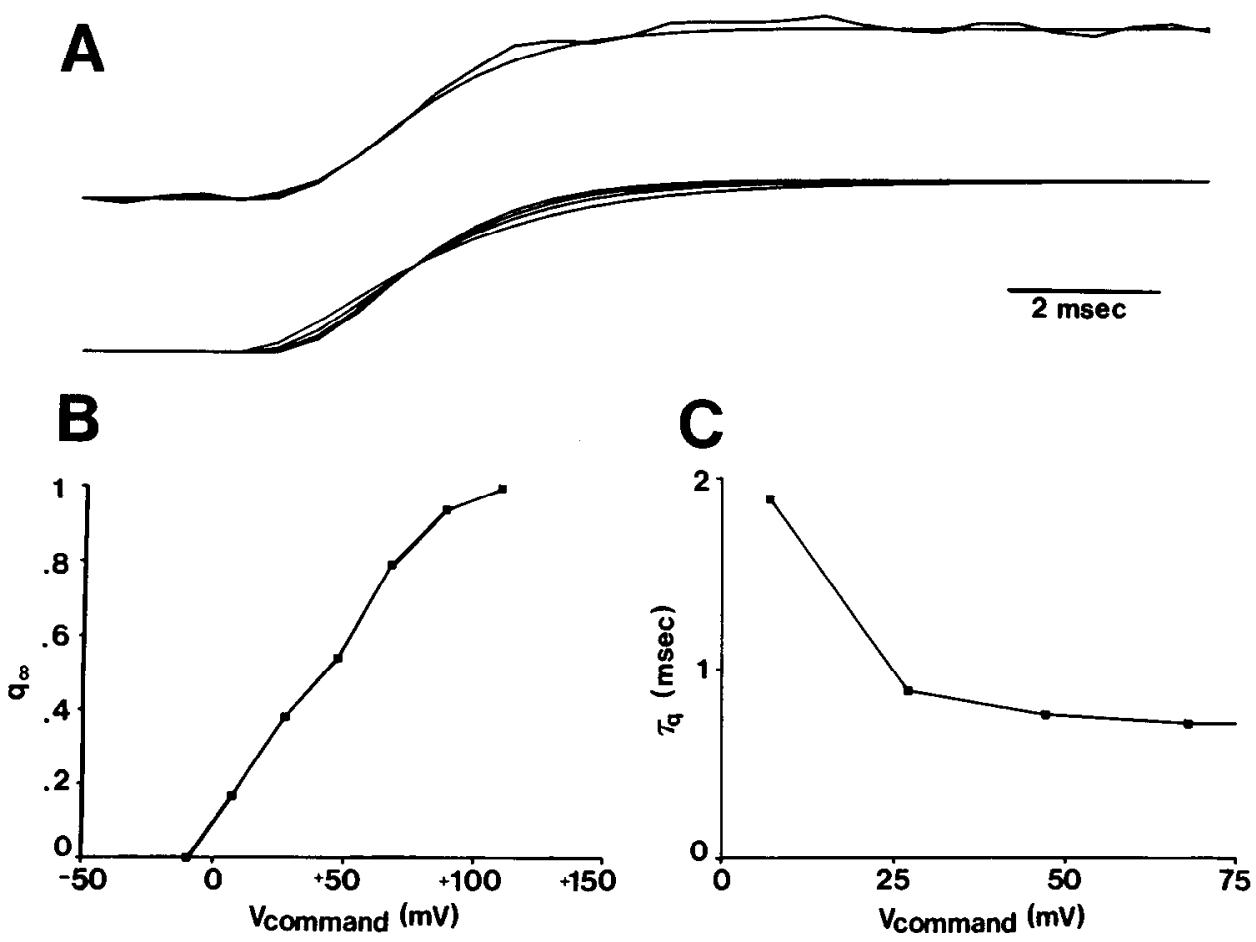
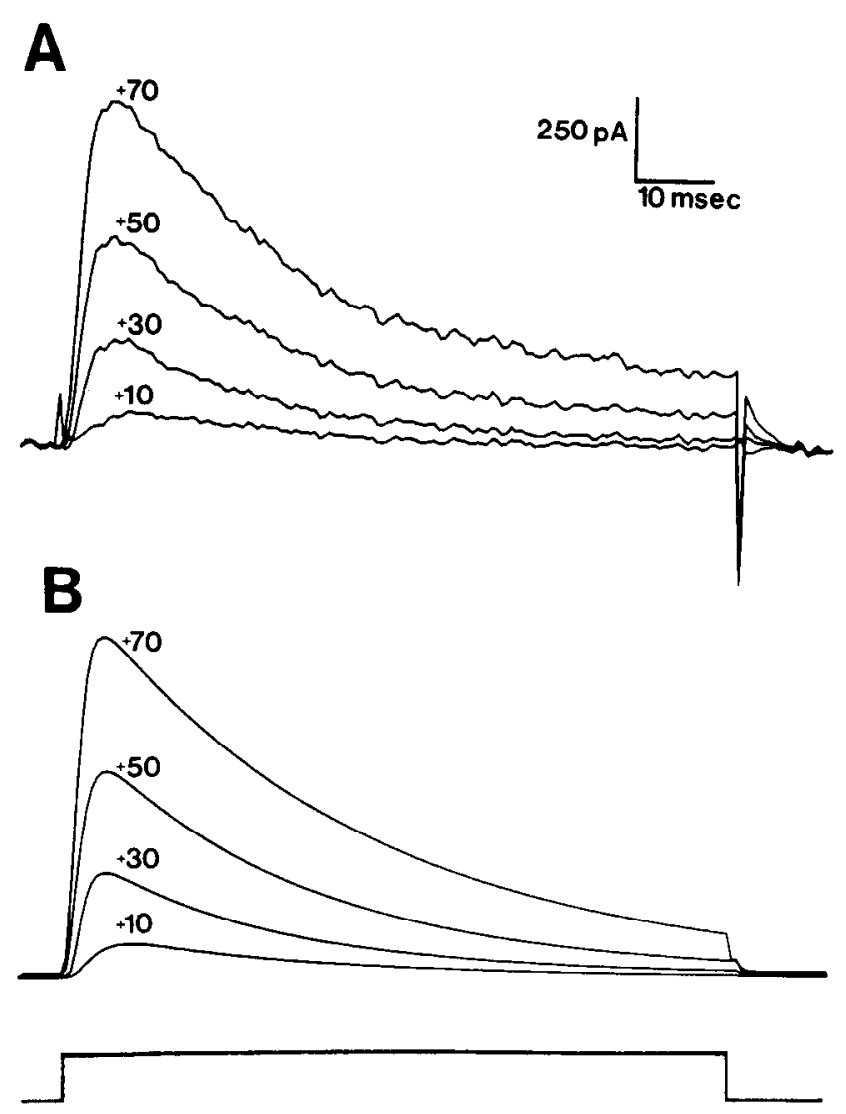

Figure 12. Comparison of measured and simulated transient outward currents. $A$, Measured current responses to command potentials. The numbers beside the current traces indicate the command potentials (in $\mathrm{mV}$ ) to which the membrane was depolarized from a holding potential of $-80 \mathrm{mV}$. The isolated current was measured using a choline/TEA bathing solution (Table 1) with $1 \mathrm{~mm}$ cobalt to block the transient inward, sustained outward, and sustained inward currents. Most of this current could be blocked by an application of $20 \mathrm{~mm}$ 4-AP. Capacitive the membrane potential approached $-30 \mathrm{mV}$, the membrane began to depolarize rapidly, generating a spike that was sometimes followed by oscillations, and finally settled to a plateau potential between -15 and $0 \mathrm{mV}$. Occasionally, an amacrine cell responded to current with 2 or 3 spikes, which damped rapidly to a plateau (not shown).

Figure $13 B$ shows the results of simulating the voltage response of the membrane to various steps of depolarizing current. It was produced by solving the differential equation described in Materials and Methods [Equation (3)]. A capacitance of 20 $\mathrm{pF}$ and an input resistance of $950 \mathrm{M} \Omega$ were chosen to match the response in Figure $13 A$ (see Table 2). The predicted plateau potentials agree well with the measured data, although for larger current steps the simulated response repolarizes further than the recorded response. The predicted spike heights also match well for larger current steps, but they fall short for steps of 72 and $90 \mathrm{pA}$. This fact, coupled with the large spike width at these current levels, indicates that the kinetics of the simulated action potential are too slow. Despite these differences, the most important feature of the response-a fast action potential followed by a plateau potential -is well characterized, suggesting that our descriptions of the currents in terms of their voltage-dependent components are valid.

\section{Discussion}

How do the ionic currents interact in the amacrine cell to generate nonrepetitive spike behavior? Our measurements provided the data about the magnitudes and kinetics of the underlying conductances so that they could be fully characterized and simulated on the basis of Hodgkin-Huxley theory (1952), as shown in Figures 4, 7, 9, and 12. The conductances were then combined

$\leftarrow$

artifacts were removed by subtraction. $B$, Simulated transient outward current, calculated using the data shown in the previous figures. Bottom trace, stimulus timing. 

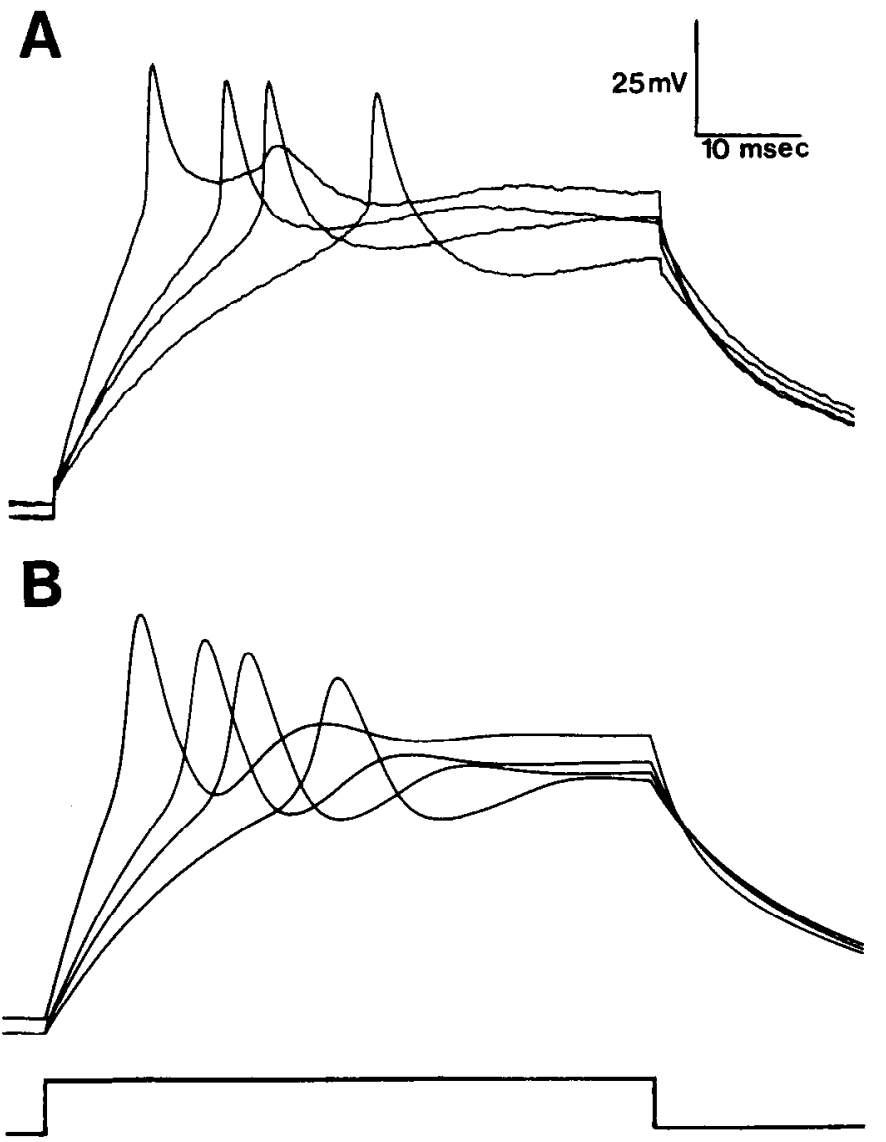

Figure 13. Comparison of measured and simulated voltage responses. $A$, Measured voltage responses to a series of suprathreshold current steps $(72,90,109$, and $168 \mathrm{pA}), 60 \mathrm{msec}$ in duration. With increasing current, the latency decreases and the plateau potential increases. $B$, Simulated voltage responses to the same series of current steps. An input (leak) resistance of $950 \mathrm{M} \Omega$ and a membrane capacitance of 20 $\mathrm{pF}$ were used. The activation curves and time constants shown in the previous figures were used for this simulation. Bottom trace, stimulus timing.

in a simulation of the voltage response to a current step (Fig. 13). This simulation allowed us to study the time course and magnitudes of the underlying conductances as they changed during the amacrine cell response, and by altering the various parameters, we were able to determine the ranges over which the nonrepetitive condition was stable.

\section{Relative magnitudes of conductances underlying the step response}

The transient sodium conductance and the calcium-activated potassium conductance are the major contributors to the spike response of the amacrine cell. The calcium conductance and the inactivating potassium conductance play only a minor or supporting role. Figure 14 shows the magnitudes of these conductances, extracted from the simulated response to a $90 \mathrm{pA}$ step. Conductance values are plotted here, but since the driving forces for sodium and calcium are taken to be roughly the same at $+50 \mathrm{mV}$, these also represent a good approximation of the relative inward current magnitudes.

$I_{\mathrm{A}}$ plays only a small role in the behavior of the cell. In response to a sustained step of current, the membrane remains more positive than $-30 \mathrm{mV}$ following the spike, and $I_{\mathrm{A}}$ remains

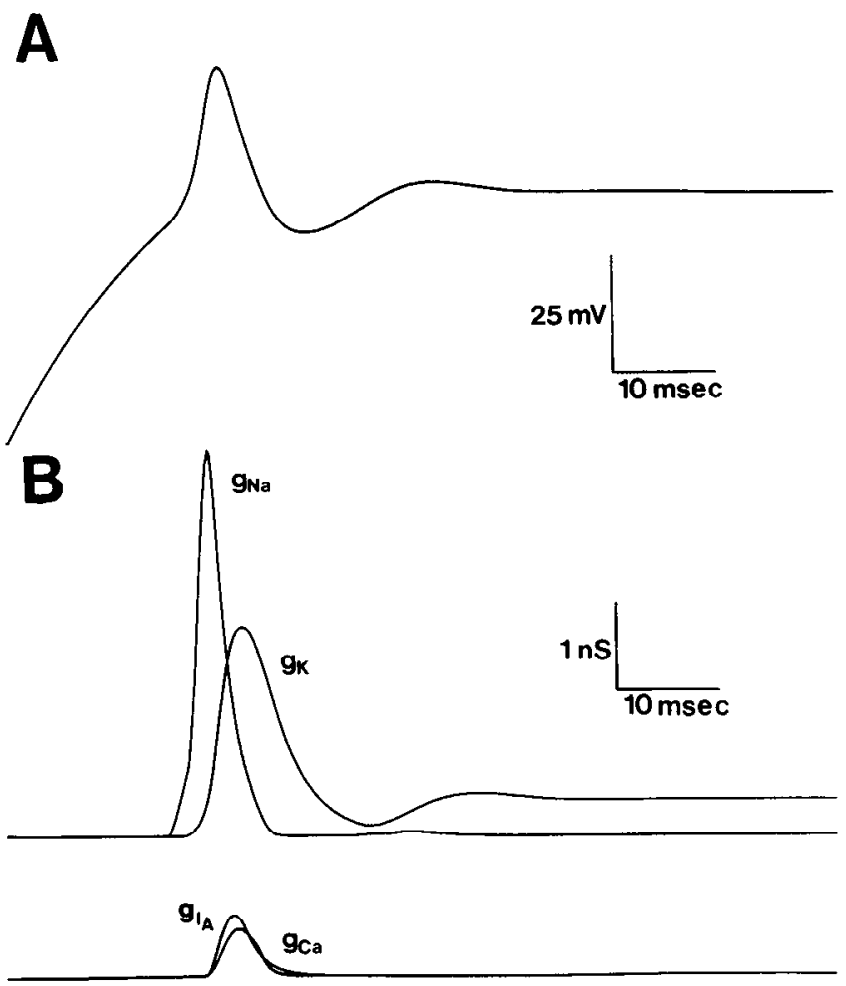

Figure 14. Simulated ionic conductances underlying the voltage response. The upper trace shows the simulated voltage response to $90 \mathrm{pA}$ of depolarizing current. Middle trace, the sodium and potassium conductances. Bottom trace, calcium and $I_{\mathrm{A}}$ conductances. The middle and bottom traces are on the same scale.

inactivated for the duration of the step. Even when fully activated, $I_{\mathrm{A}}$ is less than $25 \%$ of the total conductance gating outward current.

The calcium current is also relatively small. Its role seems to lie mostly in activating the sustained potassium current that repolarizes the membrane. In the vertebrate hair cell, an interaction between calcium and calcium-activated potassium conductances is presumed responsible for oscillatory behavior (Lewis and Hudspeth, 1983; Ashmore and Attwell, 1985). However, in this cell, the calcium current, rather than the sodium current, is the major inward current. We have ignored the kinetics of this specific interaction and considered potassium as though it were voltage-gated.

\section{Effect of calcium-activated potassium kinetics}

As mentioned in Results, the calcium-activated potassium conductance does not have the same kinetics when the membrane is depolarized to a given potential from rest, as when it is hyperpolarized to the same potential from somewhere near the peak of the calcium I-V curve. This is because changes in the rate of calcium accumulation may have slowed the kinetics of the potassium conductance. It is therefore erroneous to consider the potassium conductance as a Hodgkin-Huxley voltage-gated conductance. However, the kinetics were only about 3 times slower during the hyperpolarizing steps. This difference in kinetics can be taken into account in the simulation by slowing the potassium conductance during the repolarization phase that follows the action potential. Figure 15 shows that the result of this simulation is not very different from the result when using the faster kinetics throughout. Trace $a$ is reproduced from Figure 
Figure 15. Effect of slowing the potassium activation kinetics during repolarization. Both traces are the simulated voltage response to $90 \mathrm{pA}$ of depolarizing current. Bottom trace, stimulus timing. Trace $a$ is reproduced from Figure $13 ; b$ is the result of increasing $\tau_{n}$ by a factor of 3 during repolarization. Although the membrane does repolarize further, the characteristic single spike activity remains.

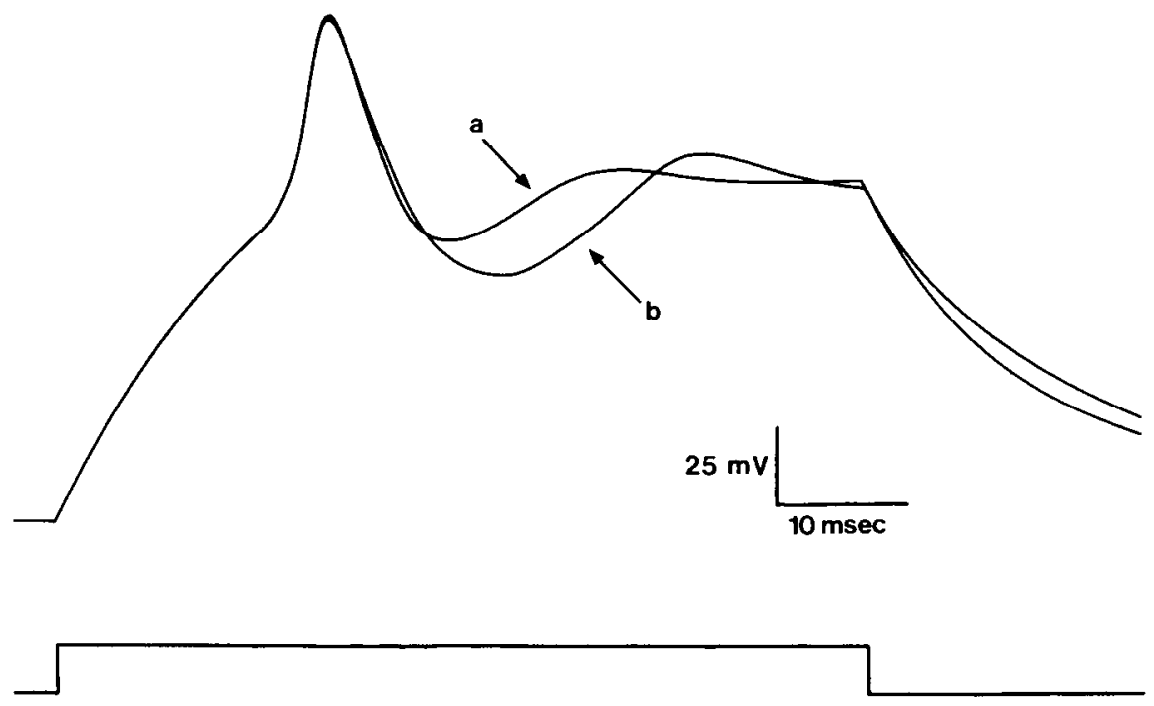

These alterations show that nonrepetitive spiking persists over a wide range of values for each of these parameters. Our results suggest that it is very difficult to generate repetitive activity by altering any one of these parameters.

\section{Slowing the potassium conductance kinetics}

If the time constant for potassium activation were very large, then following the initial spike, the potassium current would respond slowly to a change in membrane potential and could continue to repolarize the membrane to potentials more negative than the foot of its activation curve near $-30 \mathrm{mV}$ (Fig. 16). This might allow enough sodium inactivation to be removed to allow a second spike to be initiated.
A

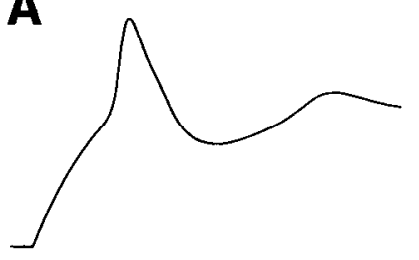

C

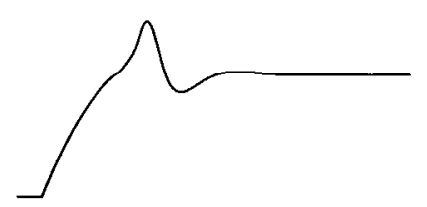

$\sqrt{-}$
B

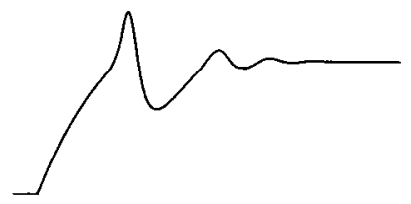

D

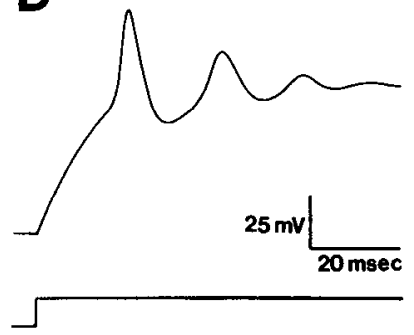

Figure 17. Effect of changing various conductance parameters on the simulated voltage response to $90 \mathrm{pA}$ of injected current (see Fig. 11B). $B$ ottom traces, stimulus timing. $A$, Increasing the potassium activation time constant, $\tau_{n}$, by a factor of 5 for all potentials does not lead to multiple spiking. $B$, Increasing the magnitude of the potassium conductance [i.e., $G_{\mathrm{K}}$ in Equation (10)] does not lead to multiple spiking. $C$, Shifting the potassium activation range by $10 \mathrm{mV}$ in the negative direction does not lead to multiple spiking. $D$, Shifting the sodium inactivation range by $10 \mathrm{mV}$ in the positive direction does not lead to multiple spiking.
Figure 16. Potassium activation vs sodium inactivation. Potassium activation (circles) is reproduced from Figure $7 B$ and sodium inactivation (triangles) from Figure $2 B$. Both are plotted on the same axes for the purpose of comparison. The 2 curves do not overlap significantly. 
Figure $17 A$ shows that even when we increased the activation time constant for potassium, $\tau_{n}$, by a factor a 5 , we were not able to simulate multiple spiking. The simulation did repolarize to a potential more negative than $-35 \mathrm{mV}$, thus moving into the inactivation range for sodium. However, the further repolarization is opposed by a response that is too sluggish to allow a rapid enough upswing in potential for adequate sodium reactivation. Therefore, a second spike will never be generated.

\section{Potassium conductance magnitude}

Even with the normal activation time constant for potassium, an artificial increase in the magnitude of the conductance could allow a further repolarization of the membrane, thereby releasing sodium from full inactivation. Figure $17 B$ shows that even when the potassium conductance is increased 5-fold, the simulated membrane does not exhibit repetitive spiking. A further repolarization is opposed by an additional factor: the larger potassium current opposes the initial upswing of the sodium current, and the spike generated is therefore smaller. A further increase in potassium conductance would decrease the initial spike still further.

\section{Shifting the potassium activation range}

Sodium inactivation and potassium activation potential ranges can be made to overlap as in repetitive spiking cells by shifting the potassium activation range in the negative direction. Under these conditions, the potassium current is able to repolarize the membrane to potentials in the sodium inactivation range. This might extinguish enough sodium inactivation to allow for another spike. However, the simulation shows that, for a $10 \mathrm{mV}$ shift of the potassium activation range, no second spike is generated (Fig. 17C). Although the membrane repolarizes to $-40 \mathrm{mV}$ following the initial spike, further repolarization is opposed by another factor: since potassium activates at more hyperpolarized potentials, the inward sodium current that develops during spike generation is overcome sooner by the outward potassium current. Therefore, the spike generated is smaller. Shifting the potassium activation range further will result in the complete absence of spike generation.

\section{Shifting the sodium inactivation range}

The result of shifting the sodium inactivation range by $10 \mathrm{mV}$ in the positive direction leads to overlap of the sodium inactivation and potassium activation curves. The result of this change is shown in Figure $17 \mathrm{D}$. Although the membrane does not spike repetitively here, a series of damped oscillations develops. Further shifting of this curve will not result in a greater tendency to spike, since it would be opposed by another factor: if the inactivation curve is shifted too much, sodium will never be sufficiently inactivated during the repolarization phase, and spiking will be depressed.

\section{Sodium conductance magnitude}

Increasing the sodium conductance permits a greater sodium current, even though the same fraction of sodium conductance is available after partial extinction of inactivation. Therefore, the membrane will depolarize further and generate more spikes. Repelitive spiking is nearly achieved, owing to an increase in the sodium conductance by a factor of 5 , as shown in Figure $18 \mathrm{~A}$. Full repetitive activity is achieved when the conductance is increased 10-fold (Fig. 18B). Increasing the sodium conduc-
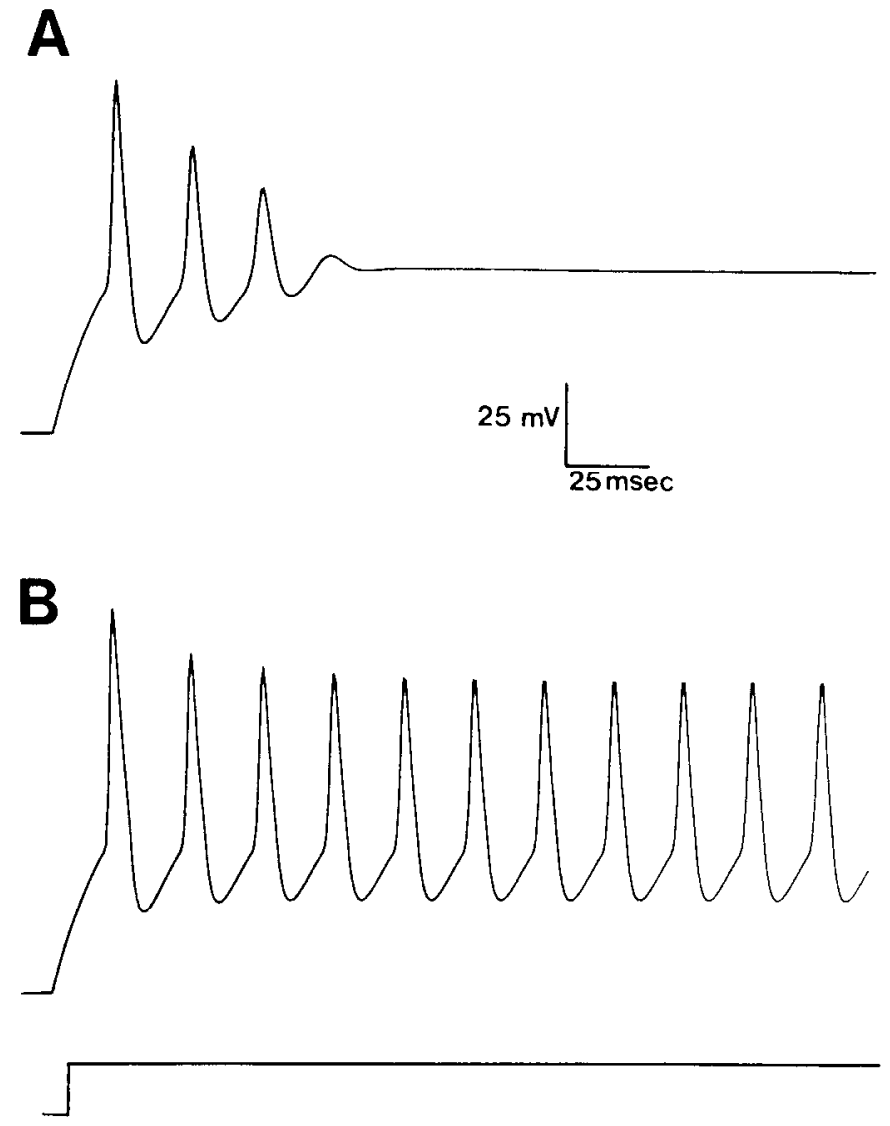

Figure 18. Effect of increasing the magnitude of the sodium conductance on the simulated voltage response to $90 \mathrm{pA}$ of injected current (see Fig. $11 B$ ). Bottom traces, stimulus timing. $A$, Increasing the magnitude of the sodium conductance by a factor of 5 increases oscillations, but does not lead to full repetitive activity. $B$, Increasing the magnitude of the sodium conductance by a factor of 10 leads to multiple spiking. The maximum depolarization is to $+46 \mathrm{mV}$, close to the sodium reversal potential of $+50 \mathrm{mV}$.

tance magnitude still further does not make much difference in the response, since the sodium equilibrium potential of +50 $\mathrm{mV}$ puts a ceiling on how far the membrane can depolarize.

\section{Conclusion}

We have shown that the gated currents are such that nonrepetitive activity is very stablc over a large range of parameter alterations. Thus, an integrated design results in conductance parameters operating together to assure single spiking. This form of activity serves to enhance the transient quality of the amacrine cell response, an important functional property that contributes to the detection of change in the retina.

\section{References}

Ashmore, J. F., and D. Attwell (1985) Models for electrical tuning in hair cells. Proc. R. Soc. Lond. [Biol.] 226: 325-344.

Barnes, S., and F. Werblin (1986) Gated currents generate single spike activity in amacrine cells of the tiger salamander. Proc. Natl. Acad. Sci. USA 83: 1509-1512.

Connor, J. A., and C. F. Stevens (1971) Prediction of repetitive firing behavior from voltage clamp data on an isolated neurone somata. J. Physiol. (Lond.) 213: 31-53.

Dacheux, R. F., and R. F. Miller (1981) An intracellular electrophysiological study of the ontogeny of functional synapses in the rabbit retina. II. Amacrine cells. J. Comp. Neurol. 198: 327-334.

Grüsser, O.-J. (1979) Cat ganglion-cell receptive fields and the role of 
horizontal cells in their generation. In The Neurosciences Fourth Study Program, F. O. Schmitt and F. G. Worden, eds., pp. 247-273, M.I.T., Cambridge, MA.

Hammill, O. P., A. Marty, E. Neher, B. Sakmann, and F. J. Sigworth (1981) Improved patch-clamp techniques for high-resolution current recording from cells and cell-free membrane patches. Pflügers Arch. Physiol. 391: 85-100.

Hodgkin, A. L., and A. F. Huxley (1952) A quantitative description of membrane current and its application to conduction and excitation in nerve. J. Physiol. (Lond.) 117: 500-544.

Kaneko, A. (1970) Physiological and morphological identification of horizontal, bipolar, and amacrine cells in goldfish retina. J. Physiol. (Lond.) 207: 623-633.

Lewis, R. S., and A. J. Hudspeth (1983) Voltage- and ion-dependent conductances in solitary vertebrate hair cells. Nature $304: 538-541$

Marchiafava, P. L., and V. Torre (1978) The responses of amacrine cells to light and intracellularly applied currents. J. Physiol. (Lond.) 276: 83-102.

Meech, R. W., and N. B. Standen (1975) Potassium activation in Helix aspersa neurones under voltage clamp: A component mediated by calcium influx. J. Physiol. (Lond.) 249: 211-239.

Reuter, H., and H. Scholz (1977) A study of the ion selectivity and the kinetic properties of the calcium dependent slow inward current in mammalian cardiac muscle. J. Physiol. (Lond.) 264: 17-47.

Saito, H.-A., and Y. Fukada (1975) Research note: Gain control mechanisms within the receptive field center of cat's retinal ganglion cells. Vision Res. 15: 1407-1410.

Stewart, W. W. (1978) Functional connections between cells as re- vealed by a highly fluorescent naphthalimide tracer. Cell 14:741759.

Thibos, L. N., and F. S. Werblin (1978) The properties of surround antagonism elicited by spinning windmill patterns in the mudpuppy retina. J. Physiol. (Lond.) 278: 101-116.

Thompson, S. H. (1977) Three pharmacologically distinct potassium channels in molluscan neurones. J. Physiol. (Lond.) 265: 465-488.

Thompson, S. H., and R. W. Aldrich (1980) Membrane potassium channels. In The Cell Surface and Neuronal Function, C. W. Cotman, G. Poste, and G. L. Nicholson, eds., pp. 49-85, Elsevier/North Holland, Amsterdam.

Werblin, F. S. (1977) Regenerative amacrine cell depolarization and formation of on-off ganglion cell response. J. Physiol. (Lond.) 264: 767-785.

Werblin, F. S., and D. Copenhagen (1974) Control of retinal sensitivity. III. Lateral interactions at the inner plexiform layer. J. Gen. Physiol. 63: 88-110.

Werblin, F. S., and J. E. Dowling (1969) Organization of the retina of the mudpuppy. II. Intracellular recording. J. Neurophysiol. 32: 339-355.

Wong-Riley, M. T. T. (1974) Synaptic organization of the inner plexiform layer in the retina of the tiger salamander. J. Neurocytol. 3: 133.

Woolum, J. C., and A. L. F. Gorman (1981) Time dependence of the calcium-activated potassium current. Biophys. J. 36: 297-302.

Wunk, D. F., and F. S. Werblin (1978) Synaptic inputs to the ganglion cells in the tiger salamander retina. J. Gen. Physiol. 73: 265-286. 